\title{
Multifunctional Chitosan-Copper Oxide Hybrid Material: Photocatalytic and Antibacterial Activities
}

\author{
Yuvaraj Haldorai and Jae-Jin Shim \\ School of Chemical Engineering, Yeungnam University, Gyeongsan, Gyeongbuk 712-749, Republic of Korea \\ Correspondence should be addressed to Yuvaraj Haldorai; yuvraj_pd@yahoo.co.in
}

Received 28 May 2013; Accepted 18 August 2013

Academic Editor: Meenakshisundaram Swaminathan

Copyright ( 2013 Y. Haldorai and J.-J. Shim. This is an open access article distributed under the Creative Commons Attribution License, which permits unrestricted use, distribution, and reproduction in any medium, provided the original work is properly cited.

Chitosan (CS) anchored copper oxide (CuO) hybrid material was prepared by chemical precipitation method. Fourier transform infrared spectroscopy (FT-IR) and X-ray diffraction (XRD) confirmed the formation of CS-CuO hybrid. Transmission electron microscopy (TEM) analysis showed the immobilization of $\mathrm{CuO}$ nanoparticles on the surface of CS. The hybrid was also characterized by thermogravimetric analysis (TGA) and zeta potential. The hybrid exhibited high photocatalytic activity as evident from the degradation of methylene blue (MB) dye. The result revealed substantial degradation of the MB dye (84\%) under UV-light illumination. The antibacterial activity of hybrid against Escherichia coli was examined by colony forming units. It was proved that the $\mathrm{CS}$ encapsulated $\mathrm{CuO}$ hybrid exhibited excellent antibacterial activity.

\section{Introduction}

In general, nanotechnology can be understood as a technology of design, fabrication, and applications of nanostructures and nanomaterials. Nanometer size structures are an intermediate form of matter which exhibit exotic physical and chemical properties different from those observed in bulk three-dimensional materials. Nanoscale oxides of transition metals are gaining continuous importance for various applications such as catalysts, passive electronic components, and ceramic materials $[1,2]$. From an environmental standpoint, heterogeneous photocatalysis is a significant cutting-edge technology for application in water purification [3]. The interest in the study of biopolymer has witnessed a steady increase, because they are environmentally friendly alternatives to synthetic, nonbiodegradable polymers. However, the poor regeneration and reuse of biopolymers have limited their adsorption properties, which may be improved by adding reinforcing compounds (fillers) and forming composites [4]. The immobilization of an appropriate catalyst onto the surface of a natural biopolymer provides a number of additional advantages including low-cost, high adsorption, high catalytic activity, and extensive potential for reuse [5].

In this regard, chitosan (CS), a linear cationic, $\mathrm{pH}$ sensitive, nontoxic, biodegradable, biocompatible polysaccharide obtained from deacetylation of chitin seems to offer numerous distinct advantages [6]. CS is a super high-capacity adsorbent for contaminant removal in water with adsorption capacity of $1000-1100 \mathrm{~g} \mathrm{Kg}^{-15}$ which is higher than the activated carbon [7]. This high adsorption of CS is due to the binding ability of CS with contaminants through hydroxyl and amino groups on the surface. The regeneration of CS by acid or base is a simple and cost effective, but the application of acid or base for CS regeneration is not technically advantageous. The large amount of wastewater generated from regeneration process needs further treatment making the process unsustainable $[8,9]$. So, the immobilization of photocatalyst onto the CS aids in removal of contaminants adsorbed by the CS and also gives antibacterial materials with improved functional properties.

Cupric oxide $(\mathrm{CuO})$, a p-type semiconductor with monoclinic structure is an interesting multifunctional material due to its promising applications in magnetic storage, solar energy transformation, electronics, sensors, batteries, and catalysis [10]. $\mathrm{CuO}$ crystal structure possesses a narrow band gap due to which it has useful photocatalytic or photovoltaic properties as well as photoconductive functionalities [11]. $\mathrm{CuO}$ nanoparticles with various morphologies have been developed by numerous methods like oxidation of copper at 
high temperature, reverse micelle, surfactant templates, solid state reactions, hydrothermal and thermal decomposition method [10, 12-15]. The immobilization of $\mathrm{CuO}$ onto $\mathrm{CS}$ resolves the recollection and reuses limitation of $\mathrm{CuO}$ to remove the contaminants adsorbed by CS in situ without use of acid or base and generating secondary pollutants and sterilizes pathogens. Recently, Gouda and Hebeish [16] prepared chitosan/CuO nanocomposite and investigated its antibacterial activity.

In this study, we synthesized a multifunctional material $\mathrm{CS}-\mathrm{CuO}$ to meet the need of high adsorption, selfregeneration, easy separation, and cost-effective dye removal from aqueous solution with enhanced antimicrobial property. The CS-CuO hybrid synthesized by precipitation method is characterized by FT-IR, XRD, zeta potential, and TEM. The $\mathrm{CS}-\mathrm{CuO}$ hybrid as a reusable photocatalyst was examined through photodegradation of MB dye. The high antibacterial activity of CS-CuO hybrid against E. coli is explored. Thus this novel CS-CuO hybrid has great potential to be used as an economic, environmental friendly, and sustainable material for dye removal with enhanced antimicrobial activity.

\section{Experimental}

2.1. Materials. Chitosan (CS) with degree of acetylation $85 \%$ and molecular weight $2.6 \times 10^{5}$ was purchased from Aldrich. Copper nitrate trihydrate $\left(\mathrm{Cu}\left(\mathrm{NO}_{3}\right)_{2} \cdot 3 \mathrm{H}_{2} \mathrm{O}\right)$, sodium hydroxide $(\mathrm{NaOH})$, acetic acid $\left(\mathrm{CH}_{3} \mathrm{COOH}\right)$, and methylene blue (MB) were of analytical grade and purchased from Aldrich. Beef extract, peptone, and agar powder were of bacteriological grade, and Escherichia coli (E. coli) (KCCM 12119) was used as a model organism for evaluation of the antibacterial activity. Deionized water was used throughout the studies.

2.2. Preparation of CS-CuO Hybrid. The CS-CuO hybrid was prepared according to the procedure given in the literature [17]. In a typical experiment, $1 \mathrm{~g}$ of $\mathrm{CuO}$ nanoparticles prepared by thermal decomposition of $\mathrm{Cu}\left(\mathrm{NO}_{3}\right)_{2} \cdot 3 \mathrm{H}_{2} \mathrm{O}$ at $350^{\circ} \mathrm{C}$ for $2 \mathrm{~h}$ was dispersed in $100 \mathrm{~mL}$ of $1 \%(\mathrm{v} / \mathrm{v})$ acetic acid, where $\mathrm{CuO}$ changed into copper cations. To this, $1 \mathrm{~g}$ of CS was added and sonicated for $30 \mathrm{~min}$ and stirred continuously until the clear sol was obtained. $\mathrm{NaOH}$ solution $(1 \mathrm{M})$ was then added dropwise until the solution attained $\mathrm{pH} 10$. The precipitate obtained was heated at $80^{\circ} \mathrm{C}$ for $5 \mathrm{~h}$ and then filtered, washed with excess of water and dried in a vacuum oven at $60^{\circ} \mathrm{C}$ for overnight.

2.3. Photocatalytic Degradation of $M B$ Dye. Methylene blue (MB) dye was used as a probe molecule to evaluate the photocatalytic activity of hybrid. The photocatalytic reaction was conducted at room temperature under UV light at a wavelength of $365 \mathrm{~nm}$. In a typical experiment, $0.4 \mathrm{mg}$ of CS$\mathrm{CuO}$ hybrid was added into the water $(10 \mathrm{~mL})$ containing $0.2 \mathrm{mg}$ of $\mathrm{MB}$ dye, followed by the addition of $1 \mathrm{~mL} \mathrm{H}_{2} \mathrm{O}_{2}$. Prior to the irradiation, the suspension was magnetically stirred in the dark for $30 \mathrm{~min}$ to establish the adsorption/desorption equilibrium of MB. A $2 \mathrm{~mL}$ of the sample was withdrawn for every $10 \mathrm{~min}$. Before analysis, the suspension was centrifuged to remove any suspended solid catalyst. The residual concentration of dye was measured using a Jasco $\mathrm{V}$ $650 \mathrm{UV}$-visible spectrophotometer.

2.4. Antibacterial Activity. E. coli was grown in a nutrient agar (DIFCO 0001) containing $3 \mathrm{~g} / \mathrm{L}$ beef extract, $5 \mathrm{~g} / \mathrm{L}$ peptones, and $15 \mathrm{~g} / \mathrm{L}$ agar in distilled water. $\mathrm{pH}$ of the medium was adjusted to 7.0. The antibacterial activity of the CS-CuO hybrid was evaluated through colony forming units (CFU) count method. Freeze-dried sample of hybrid was sliced into small pieces and sterilized at $121^{\circ} \mathrm{C}$ for $15 \mathrm{~min} .9 \mathrm{~mL}$ of the growth medium for $E$. coil was added to separate test tubes, and $0.03 \mathrm{~g} / \mathrm{mL}$ of finely sliced solid hybrid samples was added to each of the test tubes. The tubes were then seeded with $1 \mathrm{~mL}$ fresh culture of $E$. coli and incubated at $37^{\circ} \mathrm{C}$ for $12 \mathrm{~h}$. Samples were taken after $6,12,18$, and $24 \mathrm{~h}$ for CFU determination. The sample was diluted with saline water and cultured on agar plates for $12 \mathrm{~h}$. The CFU was determined by counting the colonies on agar plates, and mean values were presented from at least 3 experiments.

2.5. Characterization. Fourier transform infrared (FT-IR) spectroscopy was performed using a Jasco FT/IR-620 FT-IR spectrometer. The phase and crystallinity were characterized by using a Rigaku D/max-2500 X-ray diffractometer (XRD) with $\mathrm{Cu} \mathrm{K} \alpha$ radiation in the $2 \theta$ range of $10-80^{\circ}$. Thermogravimetric analysis (TGA) was performed on a Setaram thermal analyzer (TGA-DSC EVO, France) from 20 to $800^{\circ} \mathrm{C}$ at a heating rate of $10^{\circ} \mathrm{C} / \mathrm{min}$ under nitrogen atmosphere. Zeta potential analysis was measured using a Malvern Zetasizer Nano instrument with a laser light of wavelength $633 \mathrm{~nm}$ at $25^{\circ} \mathrm{C}$ under the Smoluchowski approximation. Microscopic images were obtained using a Hitachi H-7600 transmission electron microscope with an accelerating voltage of $100 \mathrm{kV}$. Ultraviolet-visible spectra (UV-vis) were recorded using a Jasco V-650 spectrophotometer.

\section{Results and Discussion}

Scheme 1 shows the proposed mechanism for the formation of CS-CuO hybrid. The process involved two steps. The first step is the dispersion of $\mathrm{CS}$ and $\mathrm{CuO}$ nanoparticles in acetic acid solution, where $\mathrm{CuO}$ dissolved and changed into copper cations $\left(\mathrm{Cu}^{2+}\right)$. The $\mathrm{Cu}^{2+}$ ions immediately formed coordination bonds with $-\mathrm{OH}$ and $-\mathrm{NH}_{2}$ groups of CS chains [18]. In the second step, $\mathrm{pH}$ of the solution was increased to 10 by the dropwise addition of $\mathrm{NaOH}$. The precipitate obtained was heated at $80^{\circ} \mathrm{C}$ for $5 \mathrm{~h}$, where the $\mathrm{Cu}^{2+}$ ions transformed into $\mathrm{CuO}$. The possible formation reactions of $\mathrm{CuO}$ are given below $[19,20]$. The homogeneous dispersion of $\mathrm{Cu}^{2+}$ in the CS sol aids in the generation of homogeneous CS-CuO hybrid. Consider

$$
\begin{gathered}
\mathrm{Cu}^{2+}+\mathrm{OH}^{-} \longrightarrow \mathrm{Cu}-\mathrm{O}-\mathrm{H}^{+} \\
\mathrm{Cu}-\mathrm{O}-\mathrm{H}^{+}+\mathrm{OH}^{-} \longrightarrow \mathrm{CuO}+\mathrm{H}_{2} \mathrm{O}
\end{gathered}
$$

Figure 1 shows the FT-IR spectra of pure CS and CS$\mathrm{CuO}$ hybrid. The spectrum of pure CS exhibited a band 


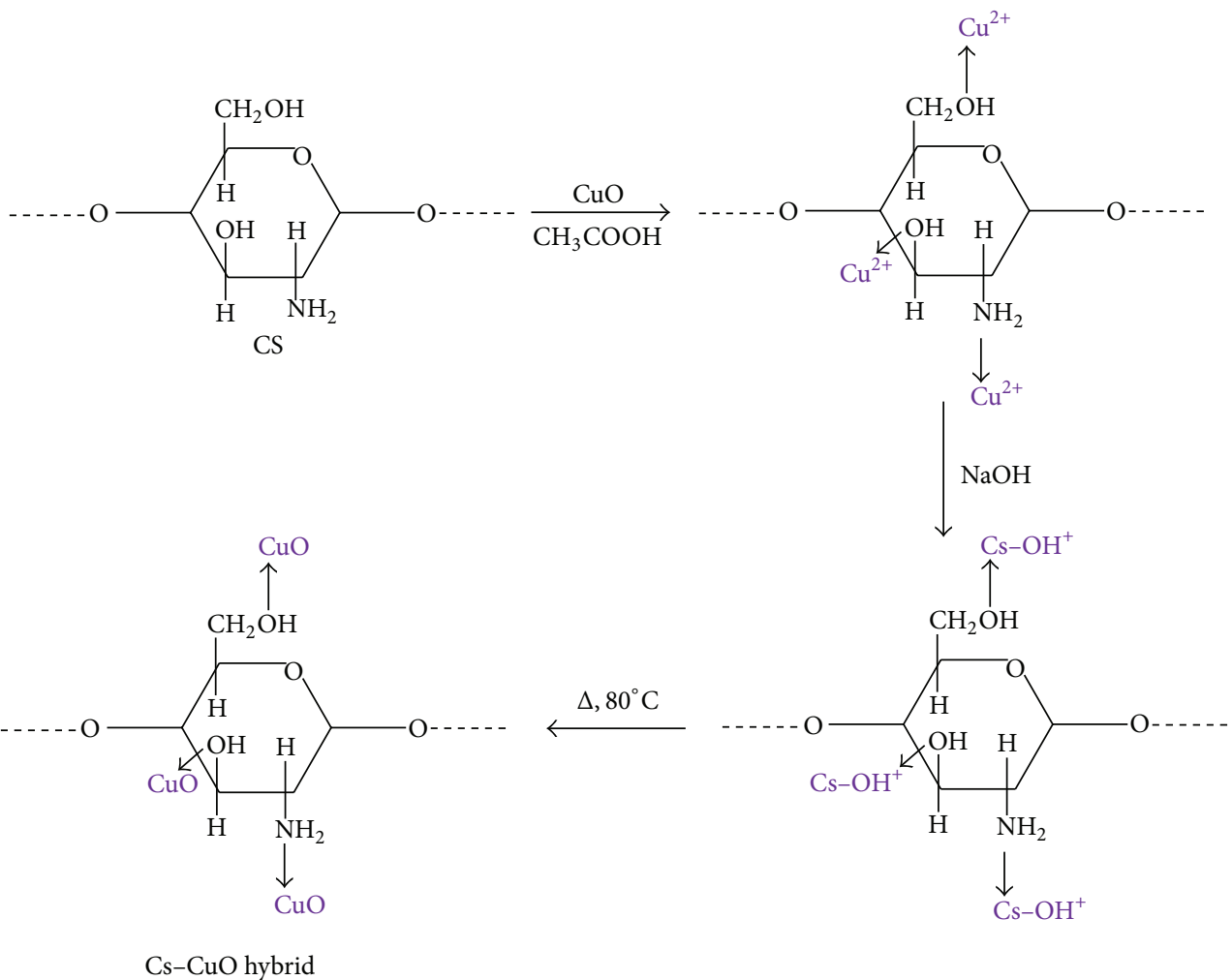

SCHEME 1: Schematic representation for the synthesis of CS-CuO hybrid.

at $3370 \mathrm{~cm}^{-1}$ was due to the stretching vibrations of $-\mathrm{OH}$ and $-\mathrm{NH}$ groups. The peak at $2876 \mathrm{~cm}^{-1}$ was attributed to the asymmetric stretching of $-\mathrm{CH}$ group in polymer, $1650 \mathrm{~cm}^{-1}$ indicated the amide I group (C-O stretching along the $\mathrm{N}-\mathrm{H}$ deformation), $1578 \mathrm{~cm}^{-1}$ was due to $-\mathrm{NH}$ deformation, $1424 \mathrm{~cm}^{-1}$ showed the $\mathrm{C}-\mathrm{N}$ axial deformation (amine group), $1375 \mathrm{~cm}^{-1}$ was attributed to the COOgroup in carboxylic acid salt, $1152 \mathrm{~cm}^{-1}$ showed the special peak of $\beta(1-4)$ glycosidic bond in polysaccharide unit, and $1047 \mathrm{~cm}^{-1}$ was assigned to the stretching vibration of C$\mathrm{O}-\mathrm{C}$ in glucose circle [21]. The CS-CuO hybrid displayed the characteristic bands of both $\mathrm{CS}$ and $\mathrm{CuO}$. The band at $520 \mathrm{~cm}^{-1}$ was ascribed to the stretching mode of $\mathrm{Cu}-\mathrm{O}$ [22]. When compared to the pure CS, the bands corresponding to the hydroxyl, amino and amide groups in the spectrum of hybrid were shifted. The shift of IR bands confirmed the interaction between the $\mathrm{CS}$ and $\mathrm{CuO}$ nanoparticles.

Figure 2 shows the X-ray diffraction patterns of CS and CS-CuO hybrid. The broad peak at $19.77^{\circ}$ in the XRD pattern of CS showed that the polymer is amorphous [23]. In the hybrid, we observed both the $\mathrm{CS}$ and $\mathrm{CuO}$ diffraction peaks. The peaks that appeared at $32.8,35.9,36.25,39.1^{\circ}, 49.1,53.5$, $58.4,62.0,66.4,68.3,72.5$, and $75.4^{\circ}$ in the hybrid were assigned to (110), (111), (111), (202), (020), (202), (113), $\overline{(311),}$ (220), (311), and (004) planes of $\mathrm{CuO}$ with high crystallinity [24]. The diffraction peaks of $\mathrm{CuO}$ are in good agreement with the monoclinic $\mathrm{CuO}$ (JCPDS card 05-0661). The result proved the successful formation of CS-CuO hybrid.
The thermal stability of CS and CS-CuO hybrid was examined by TGA from $20-800^{\circ} \mathrm{C}$ under $\mathrm{N}_{2}$ atmosphere, as illustrated in Figure 3. The two samples followed a similar decomposition trend. The as-synthesized polymer exhibited a two-step weight loss. The first weight loss (around 10\%) step in the TGA curve below $100^{\circ} \mathrm{C}$ was attributed to the loss of water. The second rapid major mass loss step in the range of $200-500^{\circ} \mathrm{C}$ was assigned to the complex dehydration of the saccharide rings, depolymerization, and decomposition of the acetylated and deacetylated units of the polymer [25]. However, it was found that the thermal stability of hybrid was higher than the pure CS which was obviously related to the existence of thermally stable $\mathrm{CuO}$. The residual mass left at $800^{\circ} \mathrm{C}$ was found to be $30.4 \%$ and $61.5 \%$ for the CS and CS$\mathrm{CuO}$ hybrid, respectively.

Zeta potential, that is, surface charge, can greatly influence the particle stability in suspension through electrostatic repulsion between particles. Zeta potential measurement is used to analyze the nanoparticle interaction with the cell membrane of bacteria, which is negatively charged. Figure 4 shows the zeta potential measurement of CS-CuO hybrid. The hybrid has a positive surface charge of about $51.5 \mathrm{mV}$, while that of $\mathrm{CuO}$ has a negative surface charge of $-32.1 \mathrm{mV}$. For CS, the positive zeta potential results from the presence of protonated amine groups. When negatively charged $\mathrm{CuO}$ reacts with the positively charged CS, the net zeta potential decreases. The shift may be attributed to the blockage of active sites on the surface of $\mathrm{CuO}$ nanoparticles by the adsorption of polymer chain. 


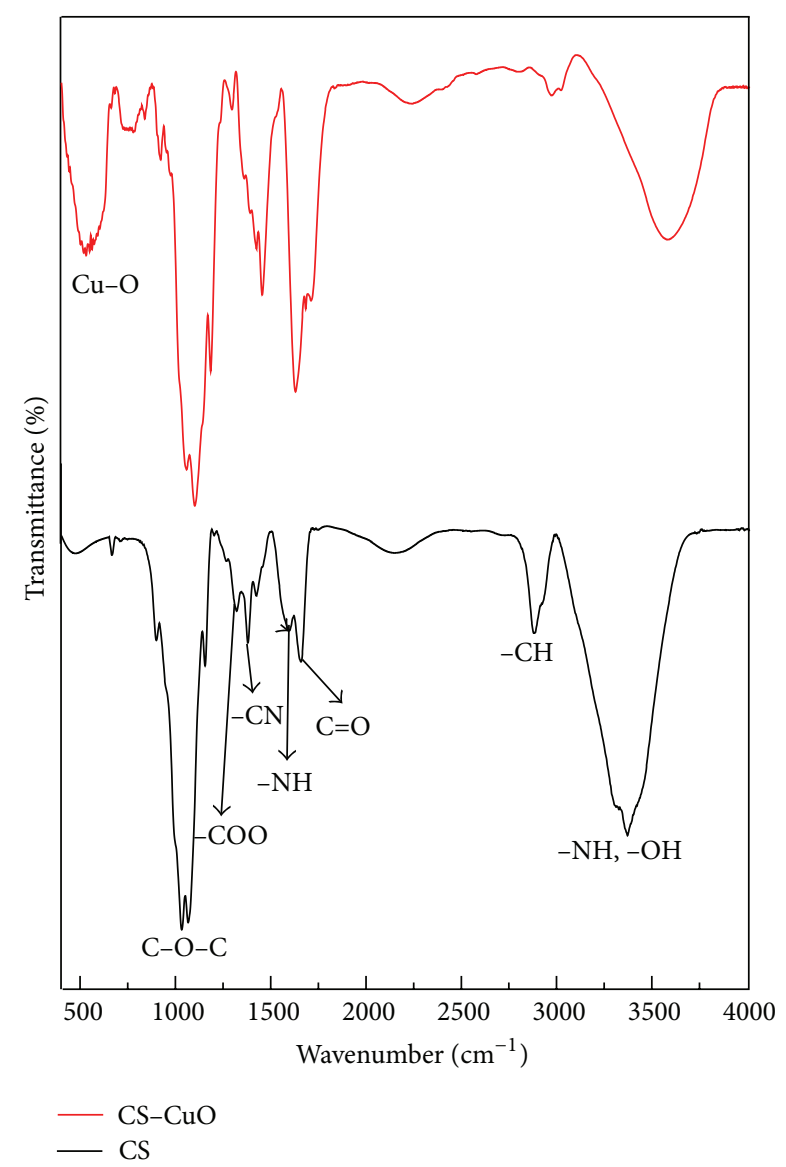

FIGURE 1: FT-IR spectra of CS and CS-CuO hybrid.

The direct evidence for the immobilization of $\mathrm{CuO}$ nanoparticles on the surface of CS was analyzed by TEM (Figure 5). The image showed that the spherical $\mathrm{CuO}$ nanoparticles exist on the CS surface with almost uniform distribution. The dark areas represent the crystalline $\mathrm{CuO}$ nanoparticles, while the bright areas represent the amorphous CS, owing to the high electron density of the $\mathrm{CuO}$ nanoparticles. The interaction between $\mathrm{CS}$ and $\mathrm{CuO}$ enhanced the properties of CS-CuO hybrid.

As a demonstration of application of such $\mathrm{CS}-\mathrm{CuO}$ hybrid, MB was chosen as a representative organic dyestuff to evaluate the photocatalytic performance. Figure 6(a) shows the typical time-dependent UV-vis absorption spectra of the $\mathrm{MB}$ dye solution during the photodegradation in the presence of CS-CuO hybrid with the aid of $\mathrm{H}_{2} \mathrm{O}_{2}$. It is seen that dye exhibited a maximum absorption peak at around $653 \mathrm{~nm}$. Note that color of the dye solutions becomes less intense, and the intensity of absorption spectra decreases gradually with increasing the irradiation time, indicating that a strong oxidation of dye has occurred in the presence of CS-CuO hybrid under UV irradiation. All these observations indicated that $\mathrm{CS}-\mathrm{CuO}$ hybrid exhibited excellent performance for the degradation of dye. Figure 6(b) shows the photocatalytic performance of various catalysts for the degradation of $\mathrm{MB}$ dye in the presence of $\mathrm{H}_{2} \mathrm{O}_{2}$. Approximately $84 \%$ of the dye was degraded by the hybrid within $30 \mathrm{~min}$. In the absence

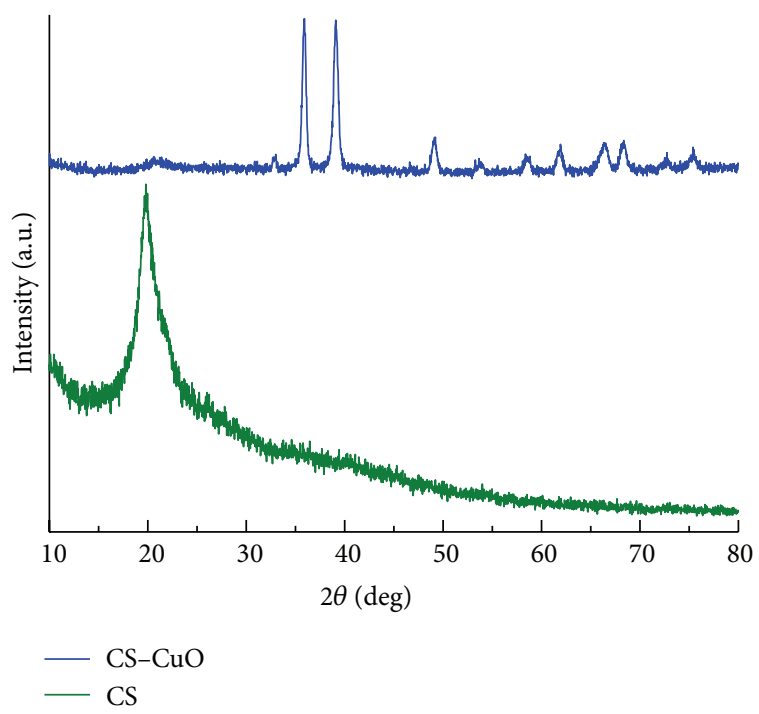

FIGURE 2: X-ray diffraction patterns of CS and CS-CuO hybrid.

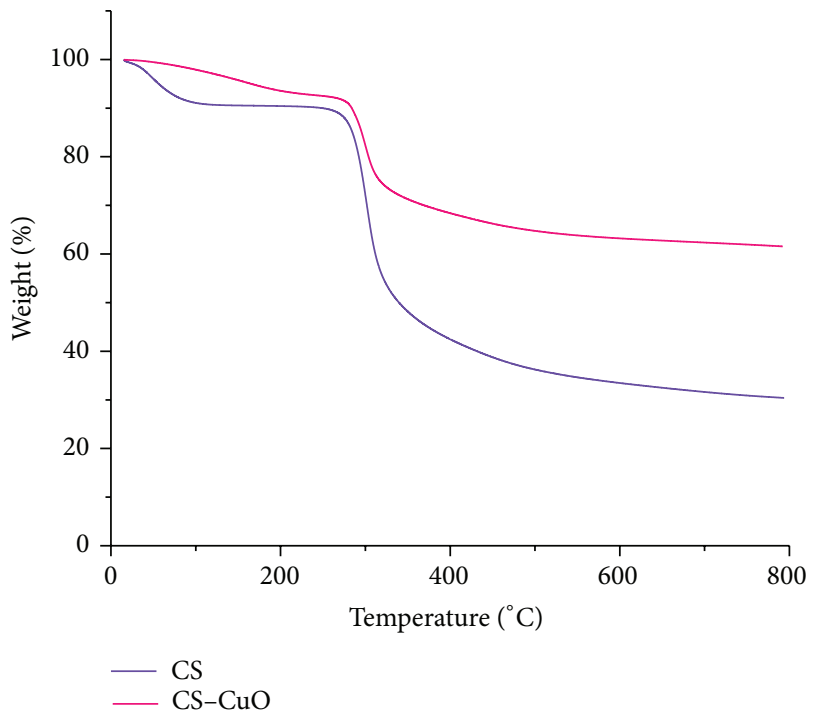

FIGURe 3: TGA curves of CS and CS-CuO hybrid.

of a photocatalyst, the dye was degraded slowly by $\mathrm{H}_{2} \mathrm{O}_{2}$ $(20 \%)$. It is seen that the degradation of the dye was greatly enhanced in the presence of photocatalyst, indicating the excellent photocatalytic activity of CS-CuO hybrid. However, the hybrid exhibited no obvious photocatalytic activity in the absence of $\mathrm{H}_{2} \mathrm{O}_{2}$ (data not shown). According to the previous report [26], the possible mechanism for the degradation of $\mathrm{MB}$ dye may be proposed as follows: the photodecomposition of $\mathrm{H}_{2} \mathrm{O}_{2}$ forms a certain amount of $\mathrm{OH}$ radicals in the presence of $\mathrm{CuO}$ first, and then these $\mathrm{OH}$ radicals degrade the $\mathrm{MB}$ dye into $\mathrm{CO}_{2}, \mathrm{H}_{2} \mathrm{O}$, and other mineralization through a series of redox reactions.

On the other hand, there is a possibility of dye degradation by a Fenton-like process. Generally, the Fentonlike process $\left(\mathrm{Cu}^{2+} / \mathrm{H}_{2} \mathrm{O}_{2}\right)$ showed lower dye degradation than the conventional Fenton reaction $\left(\mathrm{Fe}^{2+} / \mathrm{H}_{2} \mathrm{O}_{2}\right)$ [27]. In 


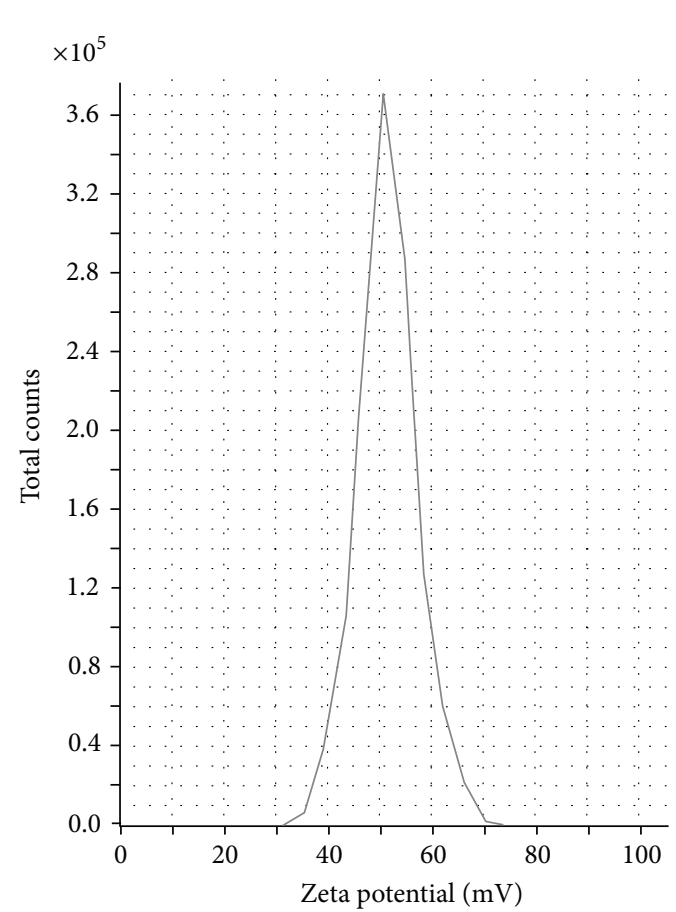

(a)

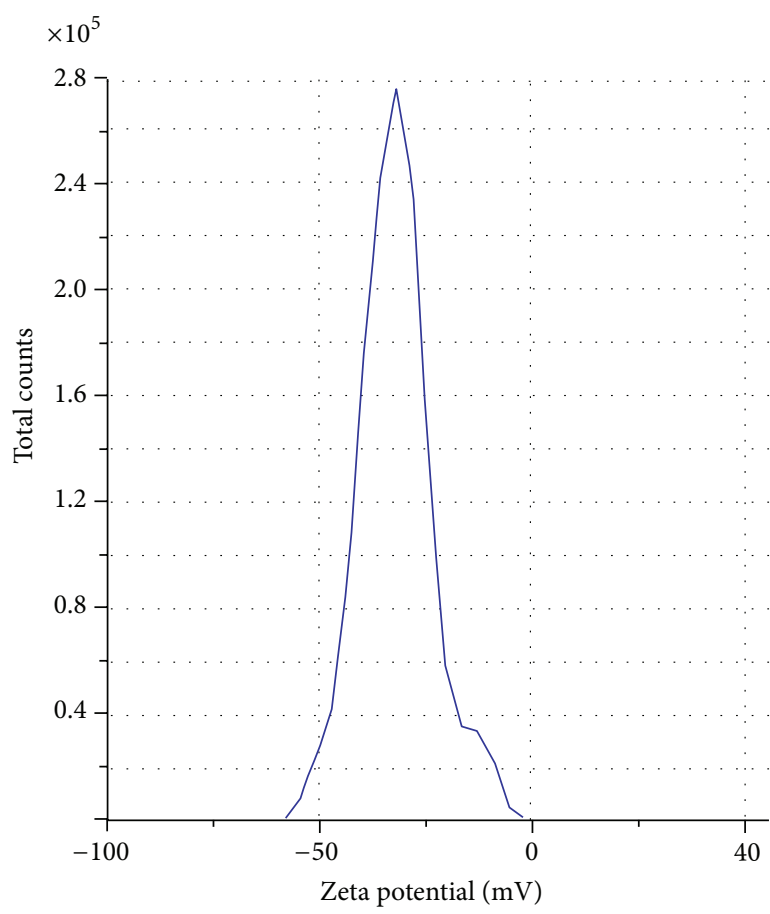

(b)

FIgure 4: Zeta potential measurement of (a) CS-CuO hybrid and (b) $\mathrm{CuO}$ at $\mathrm{pH} 7$.

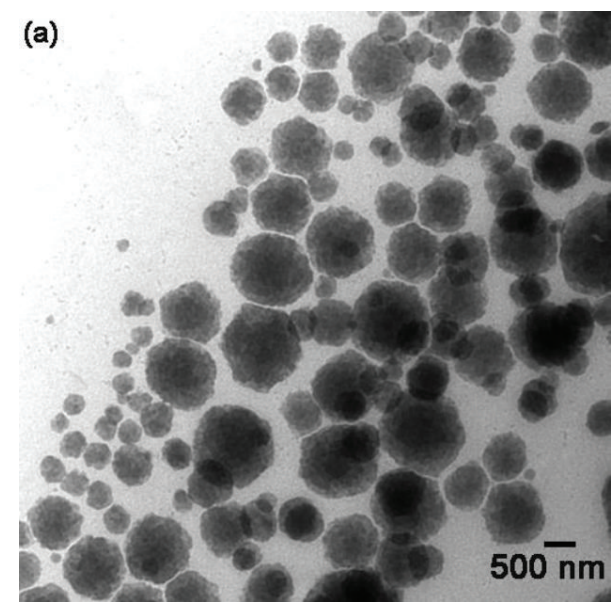

(a)

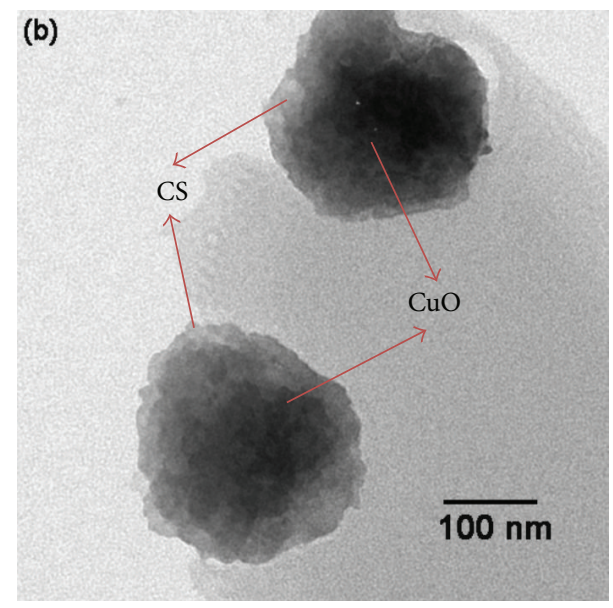

(b)

FIGURE 5: TEM images of CS-CuO hybrid (a) long view and (b) close inspection.

this system, the $\mathrm{Cu}^{2+}$ ions present in the aqueous solution immediately form coordination bonds with $-\mathrm{OH}$ and $-\mathrm{NH}_{2}$ groups of CS chains. Therefore, the $\mathrm{Cu}^{2+}$ ions were not available for Fenton-like reaction. In other words, there was no direct reaction between $\mathrm{Cu}^{2+}$ and $\mathrm{H}_{2} \mathrm{O}_{2}$.

Furthermore, the photostability of the CS-CuO hybrid was examined based on its photocatalytic performance under UV-light irradiation with three cycles, as shown in Figure 6(c). After three recycles, the catalyst did not exhibit any significant loss of activity, indicating its high stability during photodegradation process.
In general, the kinetics of photocatalytic degradation of organic pollutant on the semiconducting oxide has been established and can be described well by the apparent first order reaction:

$$
\ln \left(\frac{C_{0}}{C}\right)=k_{\text {app }} \times t
$$

where $k_{\text {app }}$ is the apparent rate constant, $C_{0}$ is the initial concentration of the dye, and $C$ is the concentration of dye at time $t$. 


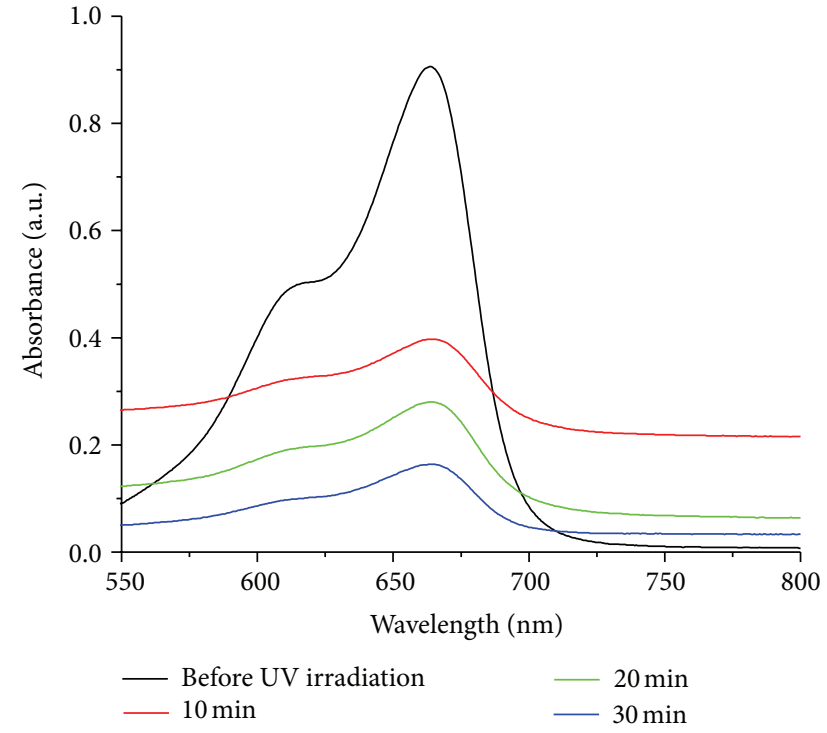

(a)

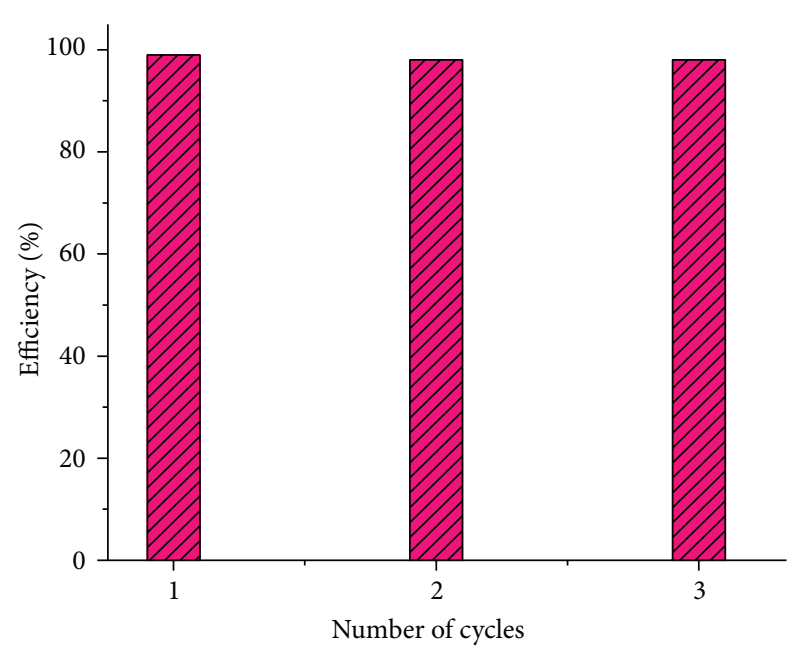

(c)

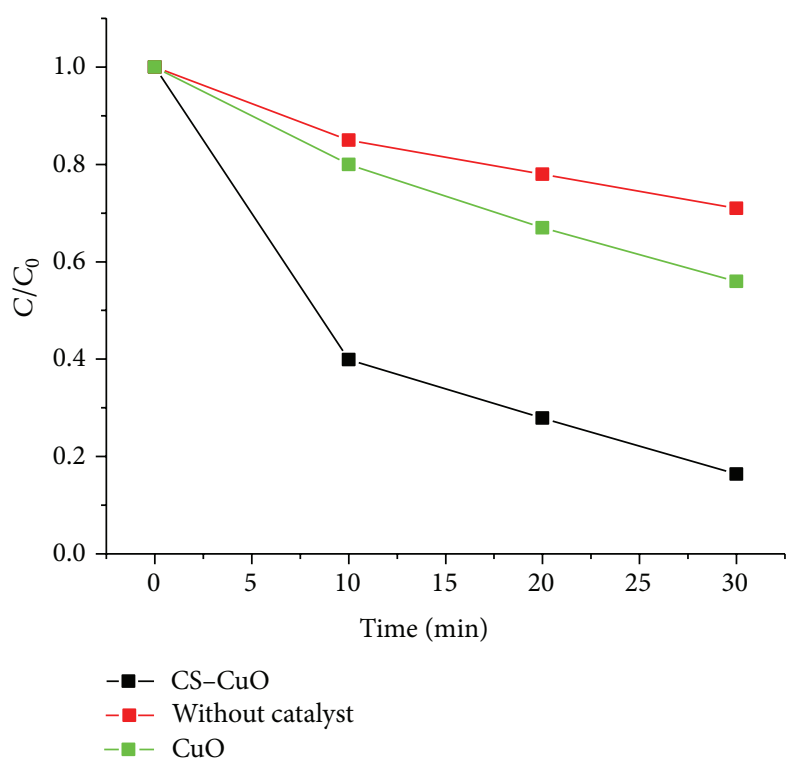

(b)

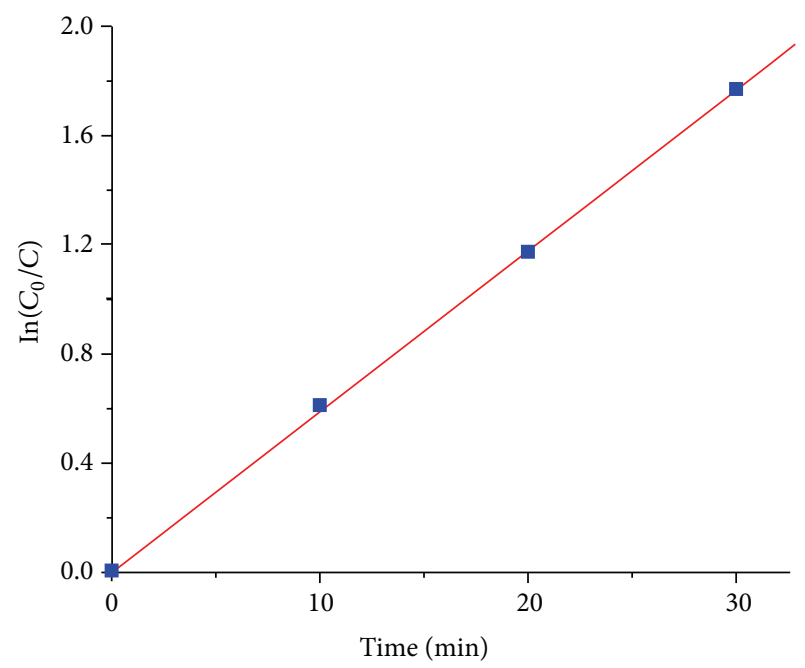

(d)

FIGURE 6: (a) UV-visible spectra of the MB solution in the presence of CS-CuO hybrid at different UV-irradiation time, (b) photodegradation of the MB dye, (c) photostability of the hybrid after three cycles, and (d) first order kinetic model for the photodegradation of MB.

Figure 6(d) shows the apparent rate constant of MB dye in the presence of photocatalyst under UV-light irradiation. The linear correlation of the plot of $\ln \left(C_{0} / C\right)$ versus time suggested a pseudo-first-order reaction for the dye. The apparent rate constant $\left(k_{\text {app }}\right)$ was determined as $0.059 \mathrm{~min}^{-1}$.

The collective results of the viability of $E$. coli after being treated with CS and CS-CuO hybrid are presented in Table 1. The viable bacteria were monitored by counting the number of CFU. As witnessed from Table 1, it is clear that the control CS sample inactivated the E. coli strain by $7 \%$ after $24 \mathrm{~h}$ of treatment which showed that almost all bacteria were alive after $24 \mathrm{~h}$. On the other hand, the CS-CuO hybrid inactivated the E. coli strain by $99 \%$ after $6 \mathrm{~h}$ of treatment. Under the same conditions only $0.7 \%$ of survivors were found after $12 \mathrm{~h}$, and complete reduction was observed at $24 \mathrm{~h}$. To visualize the
TABLE 1: Antibacterial activity of CS-CuO hybrid against E. coli.

\begin{tabular}{lcccc}
\hline $\begin{array}{l}\text { Incubation } \\
\text { time }(\mathrm{h})\end{array}$ & $\begin{array}{c}\mathrm{CFU} \\
\left(\mathrm{mL}^{-1}\right)\end{array}$ & $\begin{array}{c}\text { Reduction in } \\
\text { viability }(\%)\end{array}$ & $\begin{array}{c}\mathrm{CFU} \\
\left(\mathrm{mL}^{-1}\right)\end{array}$ & $\begin{array}{c}\text { CS-CuO } \\
\text { Reduction in } \\
\text { viability (\%) }\end{array}$ \\
\hline 0 & $28 \times 10^{5}$ & 0 & $28 \times 10^{5}$ & 0 \\
6 & $6.9 \times 10^{5}$ & 75.36 & $27 \times 10^{3}$ & 99.0 \\
12 & $1.1 \times 10^{6}$ & 60.72 & $19 \times 10^{3}$ & 99.3 \\
18 & $1.9 \times 10^{6}$ & 32.15 & $11 \times 10^{3}$ & 99.6 \\
24 & $2.6 \times 10^{6}$ & 7.15 & $2 \times 10^{2}$ & 99.9 \\
\hline
\end{tabular}

result, the digital photographs of control and E. coli treated with $\mathrm{CS}-\mathrm{CuO}$ hybrids for $12 \mathrm{~h}$ (since the bacteria grow in 


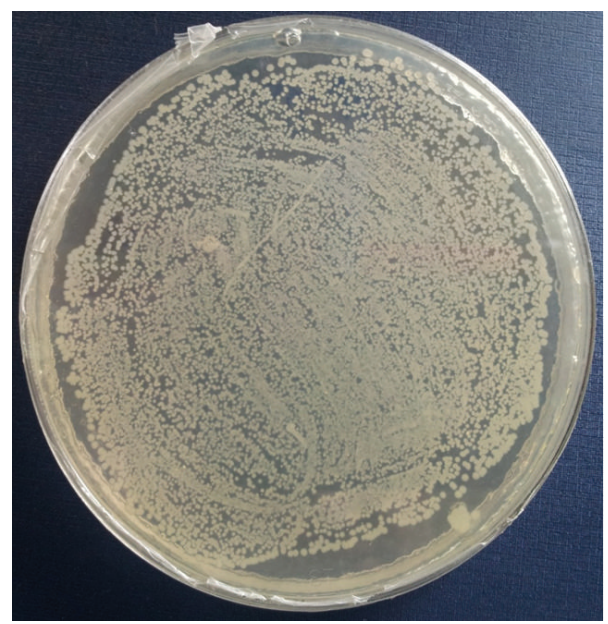

(a)

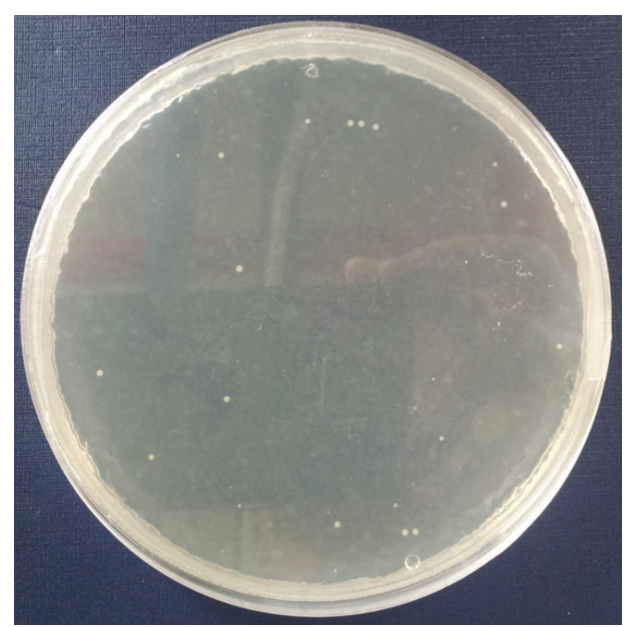

(b)

FIGURE 7: Digital photographs of E. coli (a) without and (b) with CS-CuO hybrid for $12 \mathrm{~h}$.

$12 \mathrm{~h}$ ) are shown in the Figure 7 . The result indicated that the excellent reduction in the growth of bacteria confirmed the enhanced antibacterial activity of the hybrid. The E. coli tended to be inactivated in a similar manner regarding the time of treatment. The antimicrobial mechanism of the CS was attributed to the interaction with the strongly electronegative microbial surface [16]. The CS doped with $\mathrm{CuO}$ showed enhanced antibacterial activity which perhaps attributed to the synergistic effect of the $\mathrm{CS}$ and $\mathrm{CuO}$ nanoparticles. The Gram-negative bacteria have a thin layer of peptidoglycan and more complex cell wall with two cell membranes and outer membrane and a plasma membrane. The positively charged $\mathrm{CS}-\mathrm{CuO}$ hybrid interacts with negatively charged lipidic bacterial membrane and thus changes its permeability, blocking the cells from nutrient intake, and thus ultimately affecting the cell growth and viability. It is also worth noting that the potential antibacterial activity of CS-CuO hybrid could be due to reactive oxygen species generation by the nanoparticles attached to the bacterial cells, which in turn provoked an enhancement of intracellular oxidative stress [10]. Therefore, our system showed much more efficient bactericidal activity for the sterilization of $E$. coli in an ordinary living space.

\section{Conclusion}

In this study, the CS-CuO hybrid was prepared by chemical precipitation method. The FT-IR spectrum endorsed the formation of hybrid. The thermal stability and crystallinity of the hybrid were studied by XRD and TGA. Zeta potential and TEM analysis confirmed the immobilization of $\mathrm{CuO}$ nanoparticle on the surface of CS. The hybrid catalyst showed a high photocatalytic activity of $84 \%$ for the photodegradation of the $\mathrm{MB}$ dye under UV-light irradiation for $30 \mathrm{~min}$. The result showed that the repeated use of recycled CS-CuO hybrid (three times) did not affect its photocatalytic activity significantly. In addition, the hybrid material exhibited a superior antibacterial activity of $99 \%$ within $6 \mathrm{~h}$ of treatment against $E$. coli which was measured by CFU.

\section{Acknowledgment}

This research was supported by Basic Science Research Program through the National Research Foundation of Korea (NRF) funded by the Ministry of Education, Science and Technology (2012009529).

\section{References}

[1] C. Burda, X. B. Chen, R. Narayanan, and M. A. El-Sayed, "Chemistry and properties of nanocrystals of different shapes," Chemical Reviews, vol. 105, no. 4, pp. 1025-1102, 2005.

[2] S. J. Guo and E. K. Wang, "Functional micro/nanostructures: simple synthesis and application in sensors, fuel cells, and gene delivery," Accounts of Chemical Research, vol. 44, no. 7, pp. 491500, 2011.

[3] X. Zhao, L. Lv, B. Pan, W. Zhang, S. Zhang, and Q. Zhang, "Polymer-supported nanocomposites for environmental application: a review," Chemical Engineering Journal, vol. 170, no. 2-3, pp. 381-394, 2011.

[4] S. Sarkar, E. Guibal, F. Quignard, and A. K. SenGupta, "Polymersupported metals and metal oxide nanoparticles: synthesis, characterization, and applications," Journal of Nanoparticle Research, vol. 14, no. 2, article 715, 2012.

[5] J. D. Torres, E. A. Faria, J. R. SouzaDe, and A. G. S. Prado, "Preparation of photoactive chitosan-niobium (V) oxide composites for dye degradation," Journal of Photochemistry and Photobiology A, vol. 182, no. 2, pp. 202-206, 2006.

[6] E. I. Rabea, M. E.-T. Badawy, C. V. Stevens, G. Smagghe, and W. Steurbaut, "Chitosan as antimicrobial agent: applications and mode of action," Biomacromolecules, vol. 4, no. 6, pp. 1457-1465, 2003.

[7] Z. Liu, H. Bai, and D. D. Sun, "Facile fabrication of porous chitosan $/ \mathrm{TiO}_{2} / \mathrm{Fe}_{3} \mathrm{O}_{3}$ microspheres with multifunction for water purifications," New Journal of Chemistry, vol. 35, no. 1, pp. 137-140, 2011.

[8] V. Singh, A. K. Sharma, and R. Sanghi, "Poly(acrylamide) functionalized chitosan: an efficient adsorbent for azo dyes from aqueous solutions," Journal of Hazardous Materials, vol. 166, no. 1, pp. 327-335, 2009. 
[9] V. Singh, A. K. Sharma, D. N. Tripathi, and R. Sanghi, "Poly(methylmethacrylate) grafted chitosan: an efficient adsorbent for anionic azo dyes," Journal of Hazardous Materials, vol. 161, no. 2-3, pp. 955-966, 2009.

[10] G. Applerot, J. Lellouche, A. Lipovsky et al., "Understanding the antibacterial mechanism of $\mathrm{CuO}$ nanoparticles: revealing the route of induced oxidative stress," Small, vol. 8, no. 21, pp. 33263337, 2012.

[11] G. Ren, D. Hu, E. W. C. Cheng, M. A. Vargas-Reus, P. Reip, and R. P. Allaker, "Characterisation of copper oxide nanoparticles for antimicrobial applications," International Journal of Antimicrobial Agents, vol. 33, no. 6, pp. 587-590, 2009.

[12] X. C. Jiang, T. Herricks, and Y. N. Xia, "CuO nanowires can be synthesized by heating copper substrates in air," Nano Letters, vol. 2, no. 12, pp. 1333-1338, 2002.

[13] M. H. Cao, C. W. Hu, Y. H. Wang et al., "A controllable synthetic route to $\mathrm{Cu}, \mathrm{Cu}_{2} \mathrm{O}$, and $\mathrm{CuO}$ nanotubes and nanorods," Chemical Communications, vol. 9, no. 15, pp. 1884-1885, 2003.

[14] Z. L. Wang, X. Y. Kong, X. Wen, and S. Yang, "In situ structure evolution from $\mathrm{Cu}(\mathrm{OH})_{2}$ nanobelts to copper nanowires," Journal of Physical Chemistry B, vol. 107, no. 33, pp. 8275-8280, 2003.

[15] C. K. Xu, Y. K. Liu, G. D. Xu, and G. H. Wang, "Preparation and characterization of $\mathrm{CuO}$ nanorods by thermal decomposition of $\mathrm{CuC}_{2} \mathrm{O}_{4}$ precursor," Materials Research Bulletin, vol. 37, no. 14, pp. 2365-2372, 2002.

[16] M. Gouda and A. Hebeish, "Preparation and evaluation of $\mathrm{CuO} /$ chitosan nanocomposite for antibacterial finishing cotton fabric," Journal of Industrial Textiles, vol. 39, no. 3, pp. 203-214, 2010.

[17] Y. Haldorai and J.-J. Shim, "Chitosan-zinc oxide hybrid composite for enhanced dye degradation and antibacterial activity," Composite Interfaces, vol. 20, no. 5, pp. 365-377, 2013.

[18] A. Higazy, M. Hashem, A. ElShafei, N. Shaker, and M. A. Hady, "Development of antimicrobial jute packaging using chitosan and chitosan-metal complex," Carbohydrate Polymers, vol. 79, no. 4, pp. 867-874, 2010.

[19] L.-H. Li, J.-C. Deng, H.-R. Deng, Z.-L. Liu, and X.-L. Li, "Preparation, characterization and antimicrobial activities of chitosan/Ag/ZnO blend films," Chemical Engineering Journal, vol. 160, no. 1, pp. 378-382, 2010.

[20] S. Sepulveda-Guzman, B. Reeja-Jayan, E. de la Rosa, A. TorresCastro, V. Gonzalez-Gonzalez, and M. Jose-Yacaman, "Synthesis of assembled $\mathrm{ZnO}$ structures by precipitation method in aqueous media," Materials Chemistry and Physics, vol. 115, no. 1, pp. 172-178, 2009.

[21] F. Tian, Y. Liu, K. Hu, and B. Zhao, "The depolymerization mechanism of chitosan by hydrogen peroxide," Journal of Materials Science, vol. 38, no. 23, pp. 4709-4712, 2003.

[22] A. Rahnama and M. Gharagozlou, "Preparation and properties of semiconductor $\mathrm{CuO}$ nanoparticles via a simple precipitation method at different reaction temperatures," Optical and Quantum Electronics, vol. 44, no. 6-7, pp. 313-322, 2012.

[23] L.-H. Li, J.-C. Deng, H.-R. Deng, Z.-L. Liu, and L. Xin, "Synthesis and characterization of chitosan/ZnO nanoparticle composite membranes," Carbohydrate Research, vol. 345, no. 8, pp. 994-998, 2010.

[24] Y. Li, Y. Wei, G. Shi, Y. Xian, and L. Jin, "Facile synthesis of leaf-like $\mathrm{CuO}$ nanoparticles and their application on glucose biosensor," Electroanalysis, vol. 23, no. 2, pp. 497-502, 2011.
[25] C. Peniche-Covas, W. Argüelles-Monal, and J. San Román, “A kinetic study of the thermal degradation of chitosan and a mercaptan derivative of chitosan," Polymer Degradation and Stability, vol. 39, no. 1, pp. 21-28, 1993.

[26] H. Yu, J. Yu, S. Liu, and S. Mann, "Template-free hydrothermal synthesis of $\mathrm{CuO} / \mathrm{Cu}_{2} \mathrm{O}$ composite hollow microspheres," Chemistry of Materials, vol. 19, no. 17, pp. 4327-4334, 2007.

[27] A. Aguiar and A. Ferraz, "Fe ${ }^{3+}$ - and $\mathrm{Cu}^{2+}$-reduction by phenol derivatives associated with Azure B degradation in Fenton-like reactions," Chemosphere, vol. 66, no. 5, pp. 947-954, 2007. 

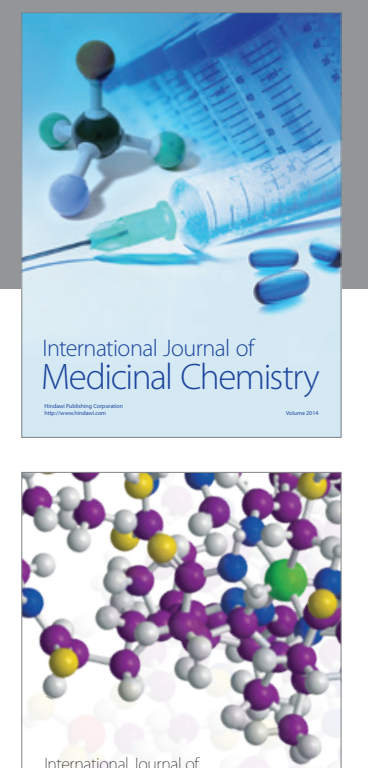

\section{Carbohydrate} Chemistry

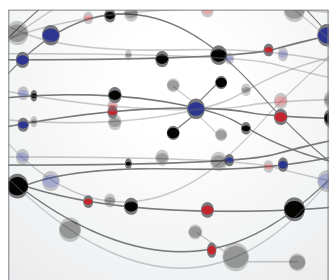

The Scientific World Journal
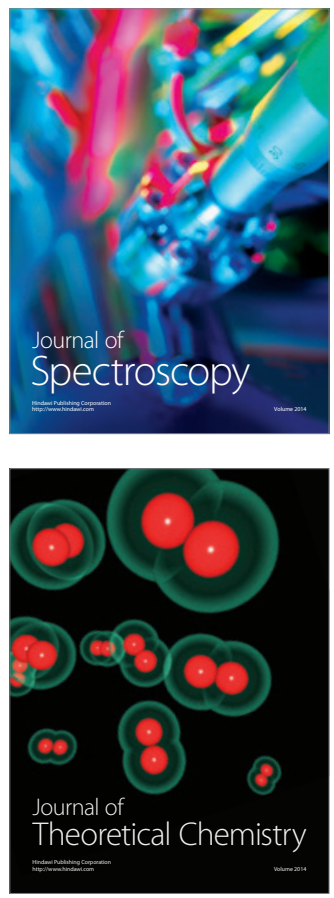
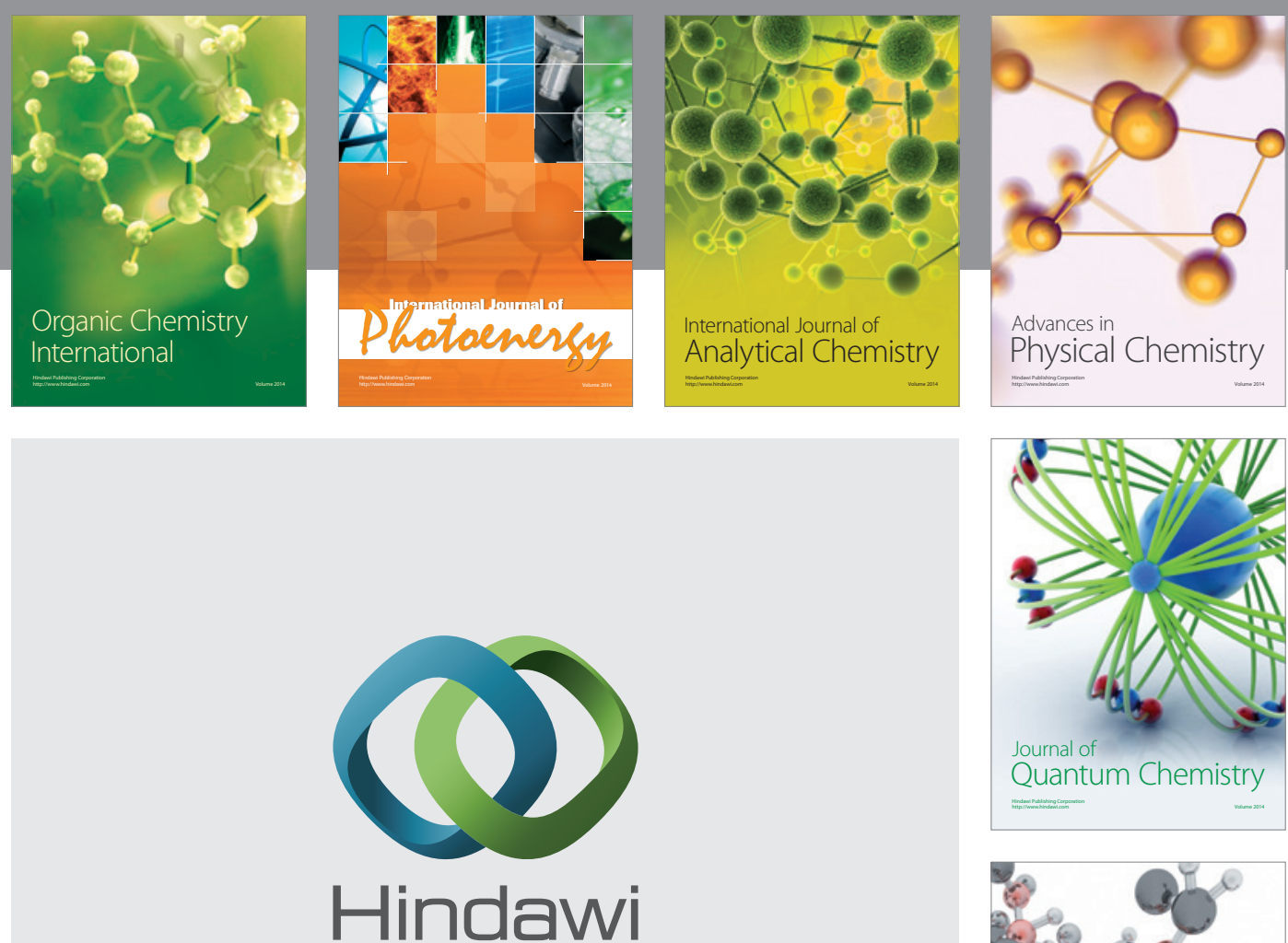

Submit your manuscripts at

http://www.hindawi.com

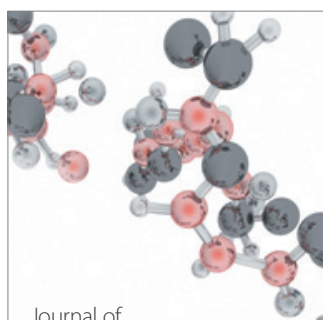

Analytical Methods

in Chemistry

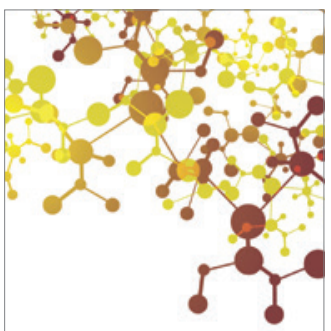

Journal of

Applied Chemistry

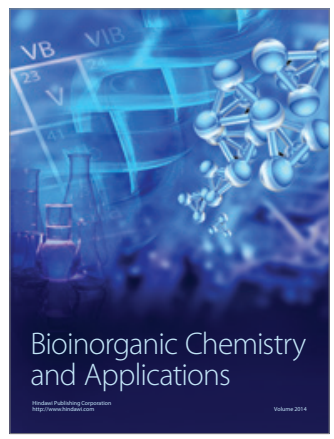

Inorganic Chemistry
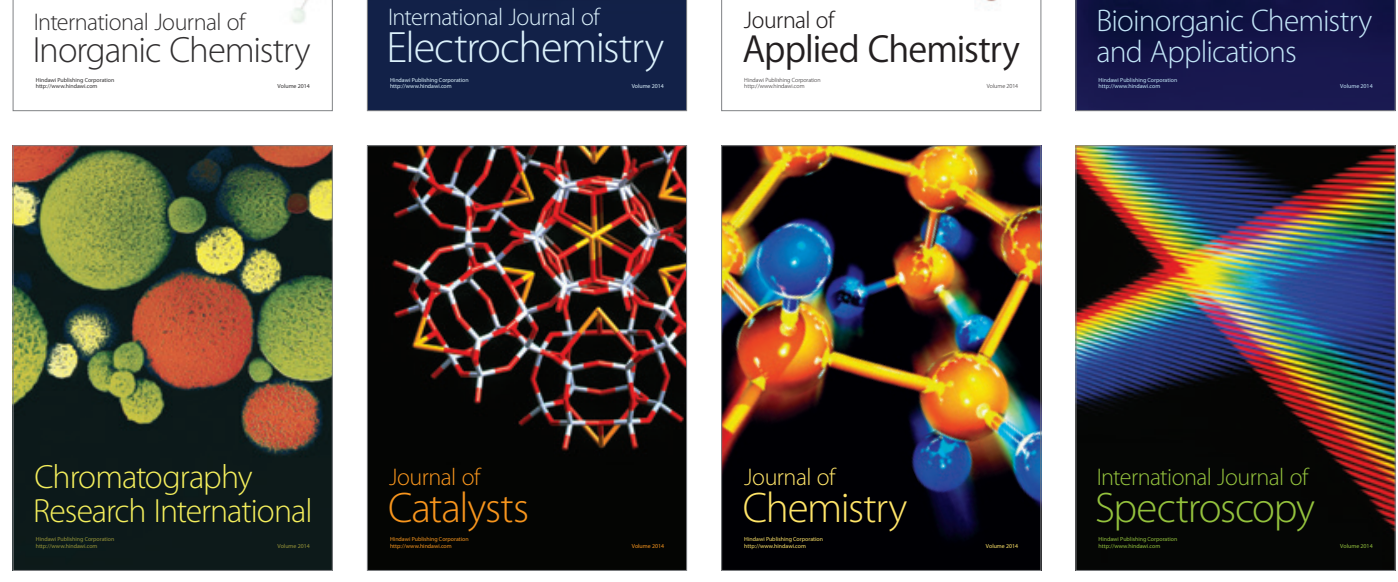